\title{
THE NATURAL HISTORY OF PERTHES' DISEASE
}

\author{
A. Catterall, London, England \\ From the Hospital for Sick Children, Great Ormond Street, London
}

Assessment of the results of treatment of Perthes' disease is confused by an incomplete knowledge of the factors that govern its natural history. The age of the patient, the stage of the disease at the time of diagnosis, and the sex are generally accepted as factors influencing the final outcome, especially if the child is treated. Frequently an unfavourable outcome occurs when these criteria promise otherwise. This paper is the result of a search for other factors upon which at the time of diagnosis we may develop a sounder prediction of the outcome in a child with Perthes' disease. So long as this knowledge eludes us we will remain undecided about the indications for treatment, its form and its influence upon the final result.

The reported results of treatment are so variable that it is difficult to be sure that the series are strictly comparable. In this connection O'Garra (1959) published evidence on a form of Perthes' disease with good prognosis, in which only the anterior part of the head was involved, confirming a concept originally introduced by Waldenström (1922). Ponseti (1961) also suggested that the final prognosis was proportional to the amount of the epiphysis involved.

The object of this paper is to suggest that the degree of epiphysial involvement can be determined by a study of the early radiological appearances, and that such diagnosis allows an effective prognosis and treatment to be advised.

\section{THE PRESENT STUDY}

This study was stimulated by the findings in a series of untreated cases of Perthes' disease studied in this department by Murley and Lloyd-Roberts (1960). These cases were carefully matched with treated controls but there was little difference in the overall results. A more detailed analysis showed that the disease in most cases was of two types. First there were mild cases (half-head disease, see Group 1 below) in whom the prognosis was very good, and secondly, severe cases (see Group 4 below) in which the prognosis was bad. In each of these types it was evident that some cases, both treated and untreated, did not behave in the manner which the age, stage at diagnosis, and sex would suggest. It was decided to investigate the problems posed by these cases.

Clinical material-Between the years 1950 and 1967, 121 patients with Perthes' disease were seen at the Hospital for Sick Children. Of these cases twelve were bilateral and twenty-five were in girls. Of the total of 133 hips, ninety-seven have been followed up for four or more years, which is the time recognised by most authors to assess the final shape of the head. The present study will be confined to these ninety-seven hips.

Of the ninety-seven hips with a follow-up of four years or more, forty-six had received no definitive treatment. This was either by design or because treatment once instituted was not adhered to, the child attending out-patients not wearing the prescribed apparatus within three months.

Care was taken to exclude those conditions such as myxoedema, and multiple epiphysial dysplasia in which a Perthes'-like change occurs.

Assessment-In the review an assessment was made of the final radiological state. The final head shape was then compared with the initial radiographic changes and the radiological course of the disease. When weight-relieving apparatus had been used arthrographs had often been performed during the disease. It was therefore possible to evaluate arthrography as an aid in understanding the natural history of the process. 
The final state of patients at the end of follow-up was graded "good", "fair" or "poor" according to the following criteria. A good result was one in which the hip caused no symptoms and had a full range of movement. Radiologically the head was round and well contained within the acetabulum, which showed no adaptive changes (Fig. 1). The medial

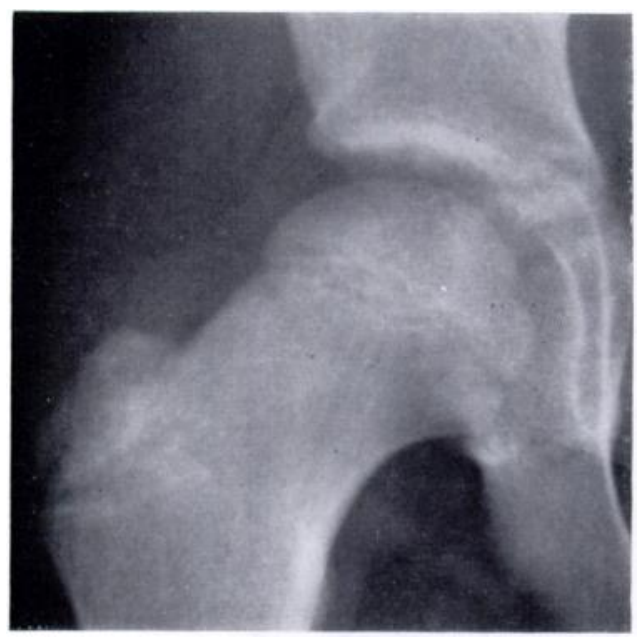

FIG. 1

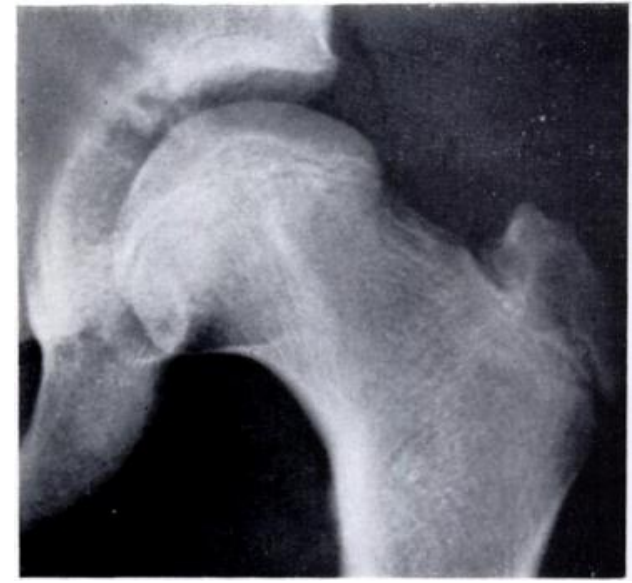

FIG. 2

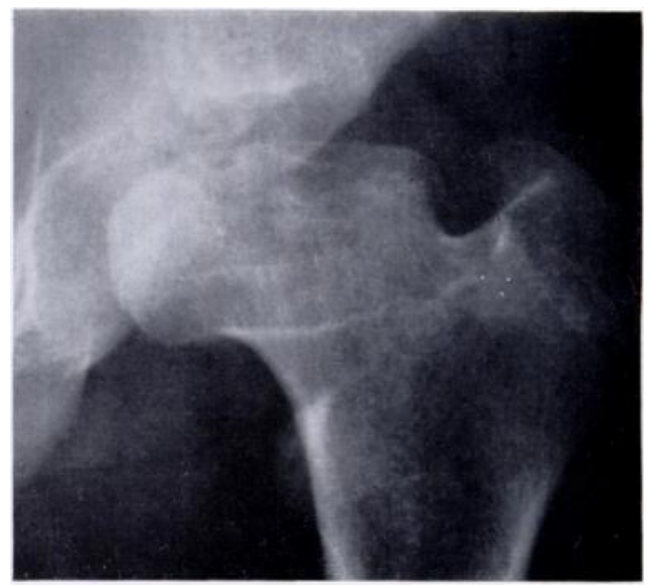

FiG. 3

Figure $1-$ Good result. The head is well contained within the acetabulum. There is some loss of epiphysial height. Figure $2-$ Fair result. The head remains round but is not completely contained within the acetabulum. There is loss of epiphysial height. Figure 3-Poor result. The head is flattened and not completely contained within the acetabulum, which shows adaptive changes. The infero-medial joint space remains wide.

joint space was not increased. Some loss of epiphysial height was accepted provided the head was round. A fair result was one in which the hip caused no symptoms but movements were a little restricted, especially medial rotation (Fig. 2). Radiologically the head was round but a little broadened and may not have been fully contained within the acetabulum, up to one-fifth being uncovered. Some adaptive changes in the acetabulum were accepted provided the head was round. There was always loss of epiphysial height. A poor result was defined as one in which the hip might not be completely free from symptoms and always showed restriction of movement, especially rotation. Radiologically the head was flattened, broad, irregular and 
at least one-fifth uncovered (Fig. 3). There were adaptive changes in the acetabulum and widening of the medial joint space.

This grading is essentially that suggested by Sundt (1949). It is useful because it reflects the probable incidence of osteoarthritis.

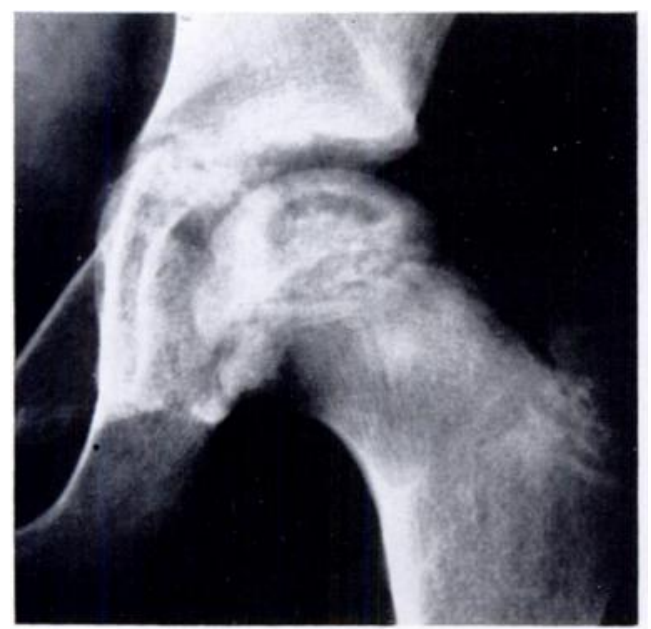

FIG. 4

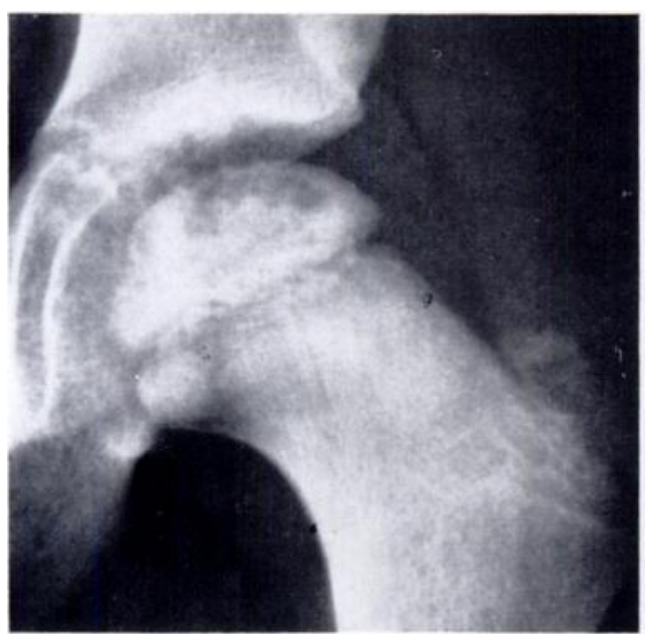

FIG. 6

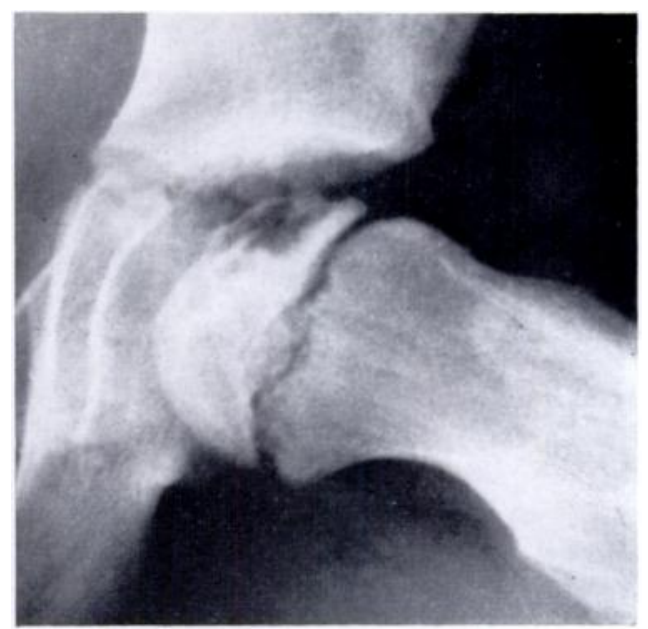

FIG. 5

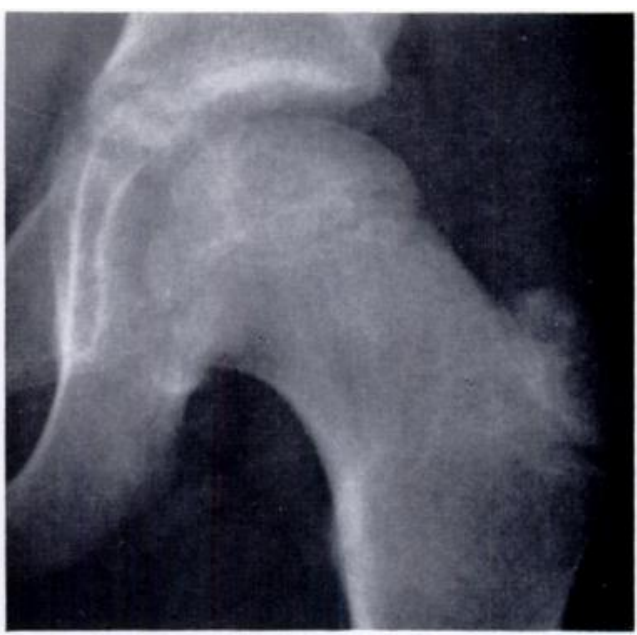

Fig. 7

Group 1. Case 1-Child aged $8 \frac{1}{2}$ years. Treatment by weight-relieving caliper. Figures 4 and 5 -After two months of limping. Figure 4 -Antero-posterior radiograph. Note the cystic appearance of epiphysis. Figure 5--Lateral radiograph: anterior part of epiphysis only involved. No sequestrum. Figure 6-Nine months later healing well established. Figure 7-After another fifteen months. Healed. Good result.

\section{GROUPING OF CASES}

Early in this study I gained the impression that there might be as many as four different forms of Perthes' disease, each running a different radiological course although clinically they were indistinguishable. Individual hips were therefore allocated to one of these groups and the end-results, age, sex and other factors were analysed. In no case was there a change from one group to another during the course of the disease.

Before describing the details of each group, I would emphasise the extreme importance of high quality radiographs in distinguishing between the forms of Perthes' disease. The vol. 53 B, No. 1, FEBRUARY 1971 
antero-posterior radiographs of both hips should be taken with the feet pointing forwards. The lateral projection is taken in the "frog" or Loewenstein position.

Group 1-In this variety only the anterior part of the epiphysis is involved (Figs. 4 to 11). It differs from other groups in that no collapse occurs and complete absorption of the involved segment occurs without sequestrum formation. In the antero-posterior radiograph the epiphysis has a rather cystic appearance, but its height is maintained. The lateral radiograph

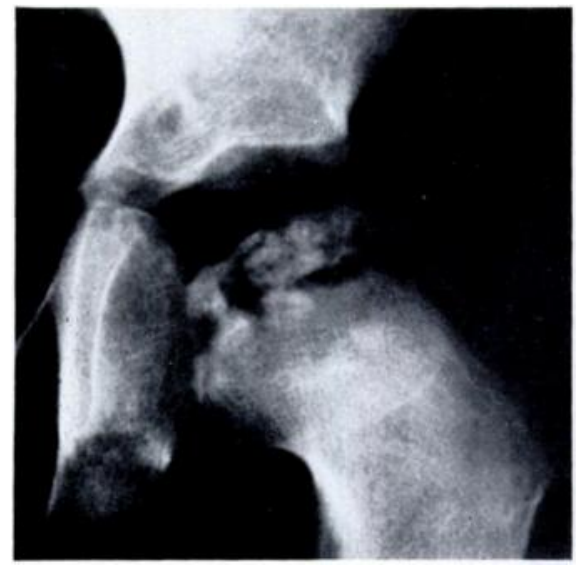

FIG. 8

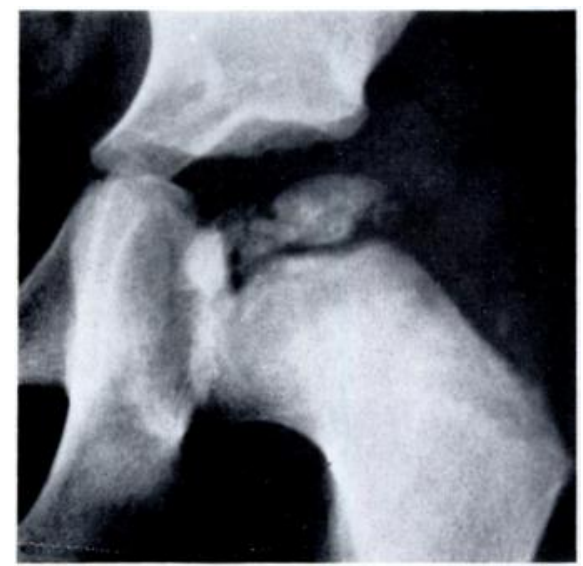

Fig. 10

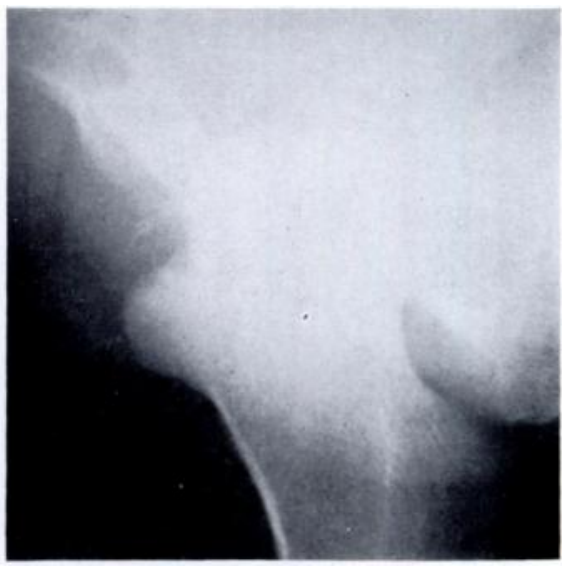

FIG. 9

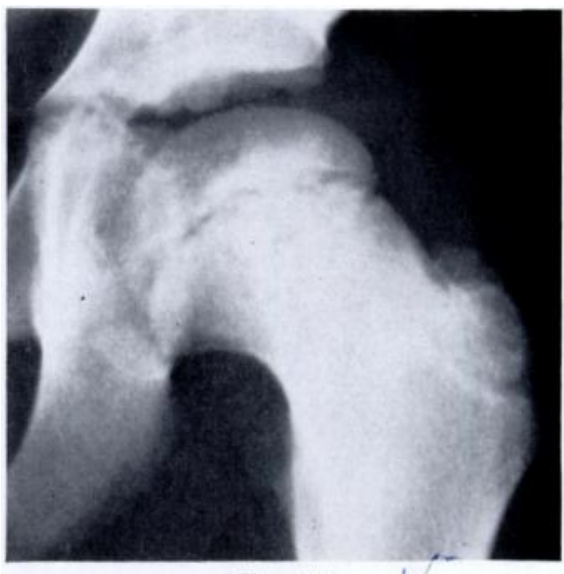

FIG. 11

Group 1. Case 2-Age at onset 41 years. No treatment. Figures 8 and 9-After six months of intermittent limping. Figure 8 -Antero-posterior radiograph. Note the cystic appearance of epiphysis. No sequestrum. Diffuse metaphysial reaction. Figure 9-Lateral radiograph. Anterior involvement only. No sequestrum, but absorption has involved the adjacent anterior metaphysis. Figure 10-Seven months later healing established. Figure 11-After another twelve months. Healed. Good result.

shows that the anterior part of the epiphysis only is abnormal. Metaphysial changes are unusual in the early phases but later a large circumscribed reaction may appear. These metaphysial changes lie beneath the involved epiphysial segment. Radiologically the course of the disease appears to be absorption of the involved segment followed by regeneration which occurs initially from the periphery.

Group 2-In this variety rather more of the anterior part of the epiphysis is involved (Figs. 12 to 19). Radiologically the major difference in the course of the disease is that the involved segment after a phase of absorption undergoes collapse with the formation of a dense collapsed segment, or sequestrum. This is absorbed before healing commences. In the antero-posterior 
radiograph the sequestrum appears as a dense oval mass with viable fragments on both medial and lateral sides. When collapse occurs the viable fragments maintain epiphysial height. On the lateral radiograph the sequestrum is separated posteriorly from the viable fragments by a "V" which, when present, is characteristic of this group (Fig. 17). If there is a metaphysial change. this is usually a well defined cyst situated anteriorly, which is transitory and disappears with healing.

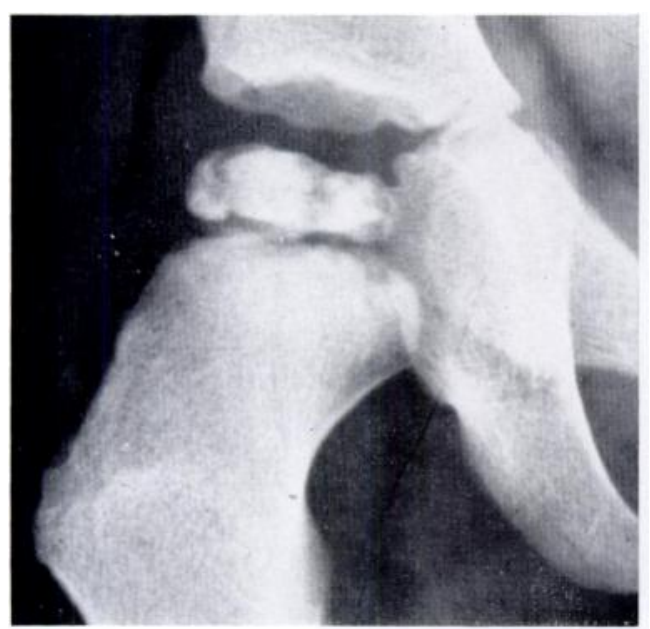

FIG. 12

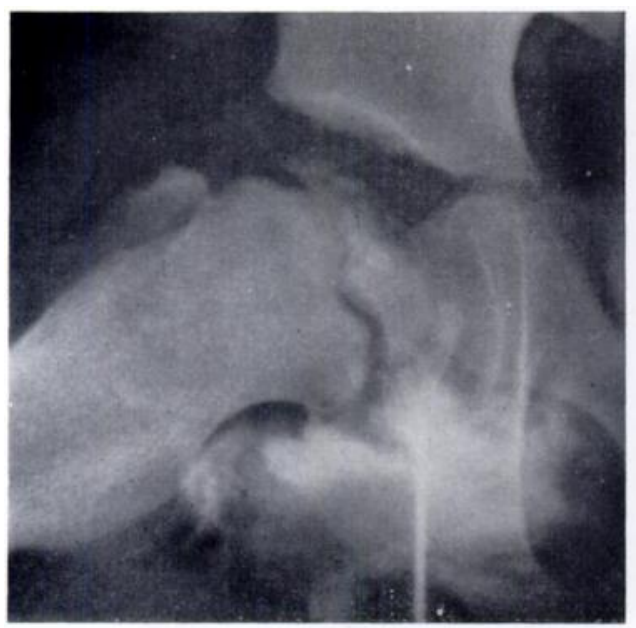

FIG. 14

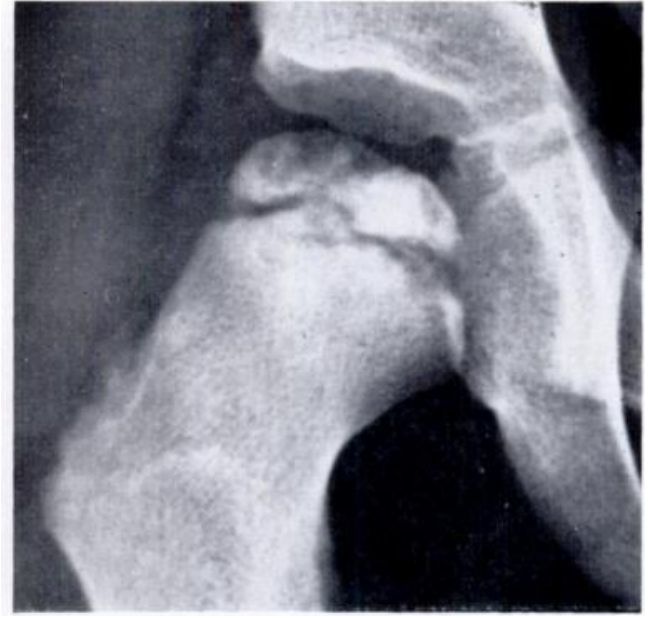

FIG. 13

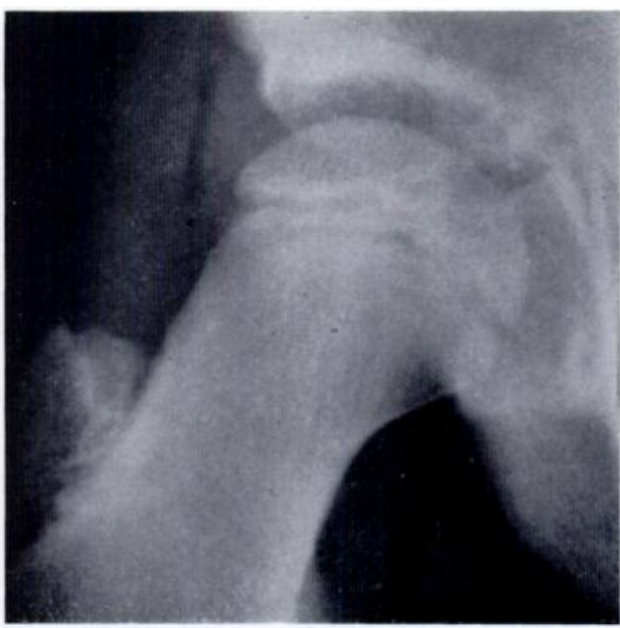

FIG. 15

Group 2. Case 3-Age at onset $4 \frac{1}{2}$ years. No treatment. Figure 12-First radiograph: six months' history of pain and limping. There is a large central sequestrum with small viable fragments. The head is contained within the acetabulum. Figures 13 and 14-Eleven months later. The sequestrum is partly absorbed. The epiphysial height is maintained. The lateral radiograph shows that only half the head is involved. Figure 15-Six years later. Healed. Good result.

Group 3-In this variety only a small part of the epiphysis is not sequestrated (Figs. 20 to 23). The antero-posterior radiograph during the early phases reveals the appearance of a "head within a head" while in the later phases there is a collapsed sequestrum centrally placed, with very small normal textured segments on the medial and lateral sides. Frequently the lateral fragment is small and osteoporotic, appearing as specks of calcification. When collapse occurs this osteoporotic segment with its associated growth plate becomes displaced in an antero-lateral direction producing with growth broadening of the neck. On the lateral 
radiograph it will be seen that only a very small portion of the posterior part of the head is uninvolved. The junction of the sequestrum and the viable segment is often not definable, the two blending in an area of sclerosis. The course of the disease is essentially the same as in Group 2, in that the sequestrum once formed is gradually absorbed before the regeneration begins from the periphery. The osteoporotic segment may become apparent only at this stage when it regenerates in its displaced position. Metaphysial changes are more generalised and when extensive are frequently associated with broadening of the neck.

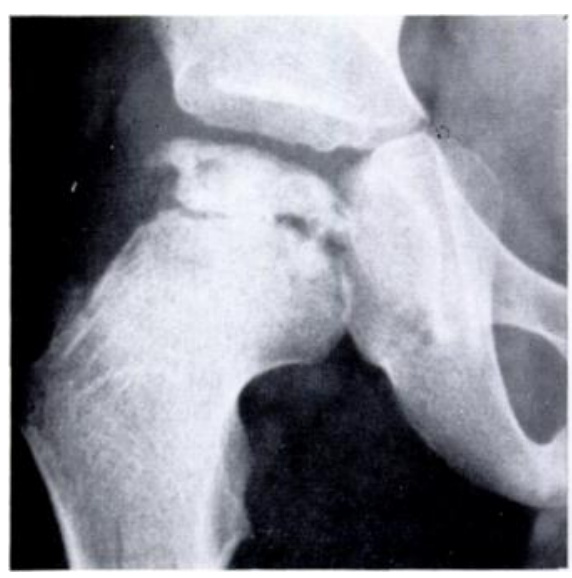

FIG. 16

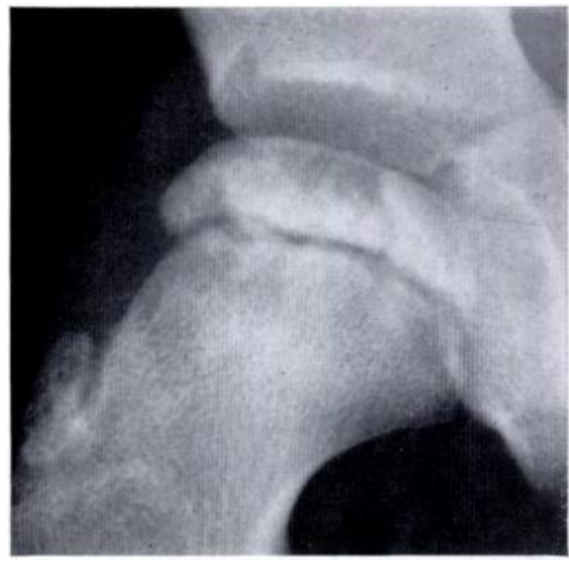

FIG. 18

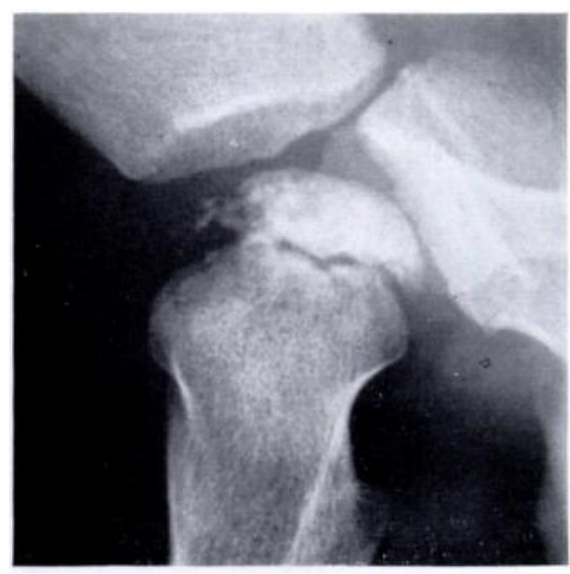

FIG. 17

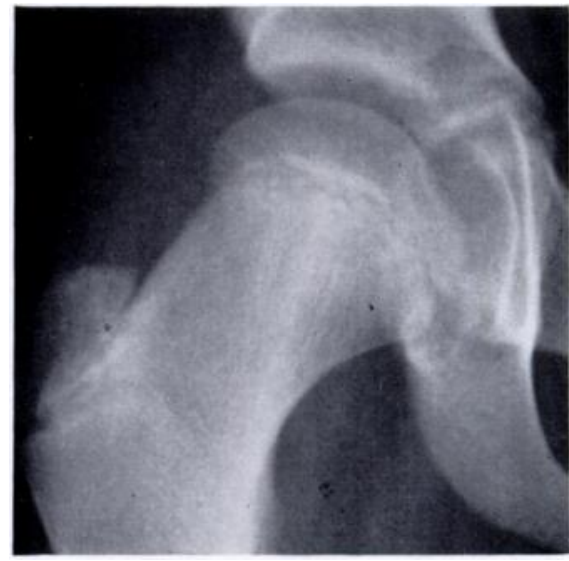

FIG. 19

Group 2. Case 4-Age at onset $4 \frac{1}{2}$ years. Treatment by weight-relieving caliper. Figures 16 and 17-After six months of limping. Cystic appearance of epiphysis and small central sequestrum. Gage sign present. The lateral radiograph shows that the anterior part of the epiphysis is involved. There is a small sequestrum embraced by a ' $\mathrm{V}$ ' of viable epiphysis. Figure 18-Eight months later. Sequestrum reabsorbed. Healing commenced. Figure 19Five and a half years later good result, with remodelling.

Group 4 -In this variety the whole epiphysis is now sequestrated (Figs. 24 to 31). On the antero-posterior radiographs total collapse of the epiphysis produces a dense line. There is an early loss of the height between the growth plate and the roof of the acetabulum indicating flattening of the head. Displacement of the epiphyses can occur not only anteriorly but also posteriorly producing a mushroom-like appearance of the head. On the lateral radiograph there is no posterior viable portion, there being only an irregular linear opacity replacing the epiphysis. As in Group 3 metaphysial changes may be extensive. 


\section{RESULTS}

General-Before the results of the individual groups are compared it is necessary to make several general observations. Considering all cases there were ninety-seven hips in eighty-nine patients seen between 1950 and 1964, of which eight cases were bilateral. The average age at diagnosis was four and a half years and the age distribution from one year nine months to ten years. The ratio of boys to girls was four to one. This did not alter with age (Fig. 33). The average follow-up was ten and a half years with a scatter of from eighteen to four years.

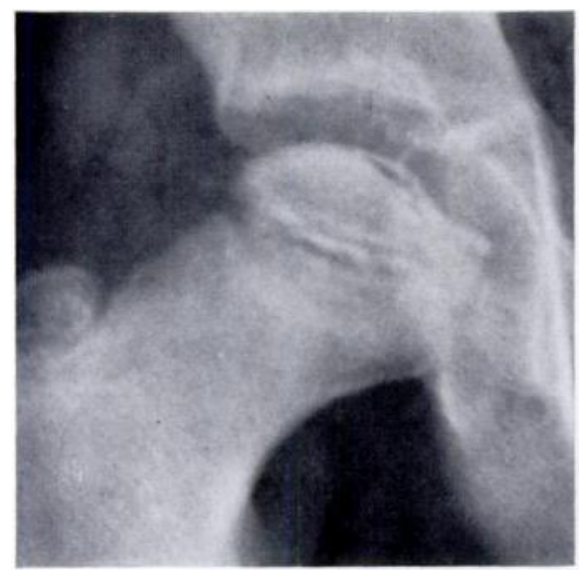

FIG. 20

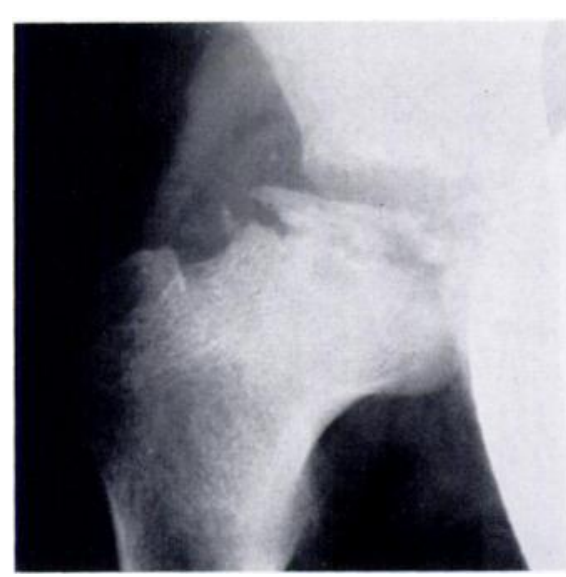

Fig. 22

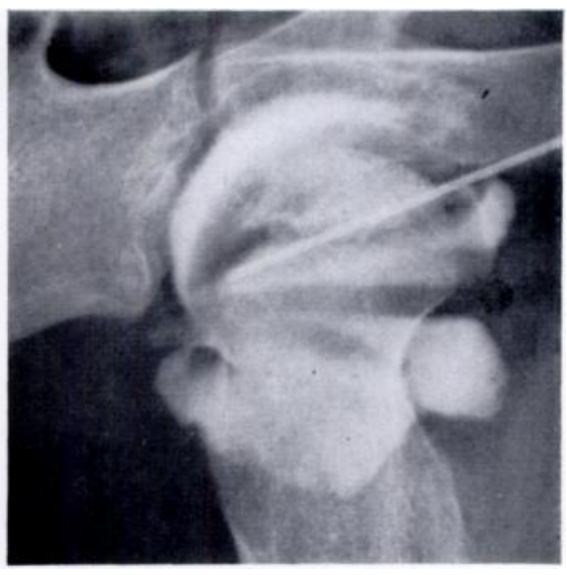

Fig. 21

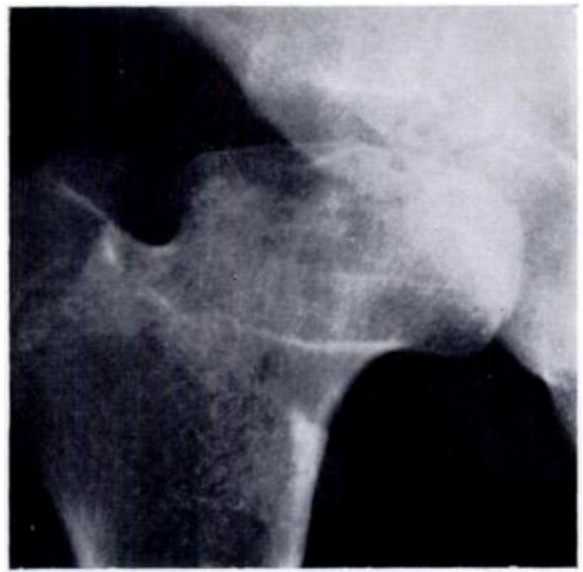

Fig. 23

Group 3. Case 5-Age at onset $5 \frac{1}{2}$ years. Treatment by weight-relieving caliper. Figures 20 and 21-After two months of pain in groin. Large sequestrum. Lateral segment. Segmentum small osteoporotic. Small speck of calcification just lateral to epiphysis. Lateral radiograph shows that the sequestrum involves almost the whole epiphysis. Small posterior portion is viable. Figure 22-Fifteen months later. Head very flattened but starting to heal. The calcified area is re-forming, but outside the acetabulum. Figure 23-Four and a half years later. Healed. Poor result.

Of the forty-six untreated hips twenty-seven were graded good, eleven fair and eight poor, whereas of the fifty-one treated hips thirty were good, thirteen fair and eight poor. The prognosis varied with age (Fig. 32). Fair and poor results were present at all ages, but over the age of five years there was a considerable reduction in the proportion of good results. As previously reported, the prognosis was worse in girls than boys. Twelve cases had a clear 


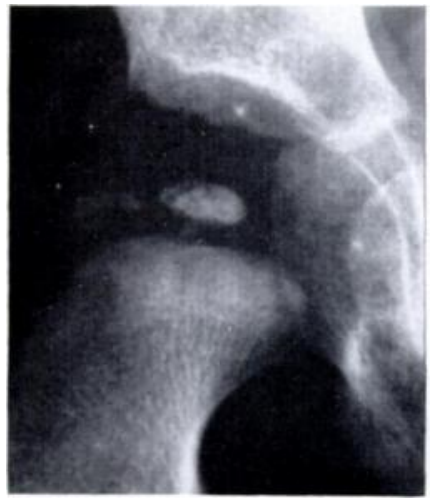

FIG. 24

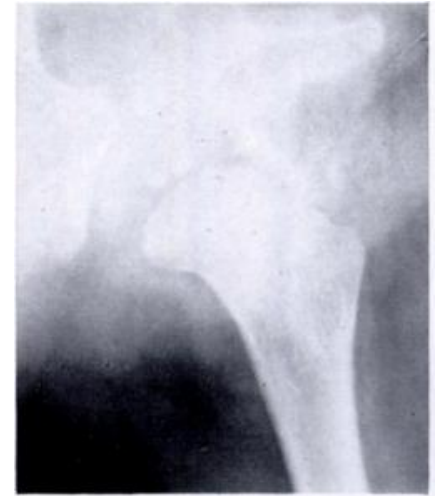

FIG. 25

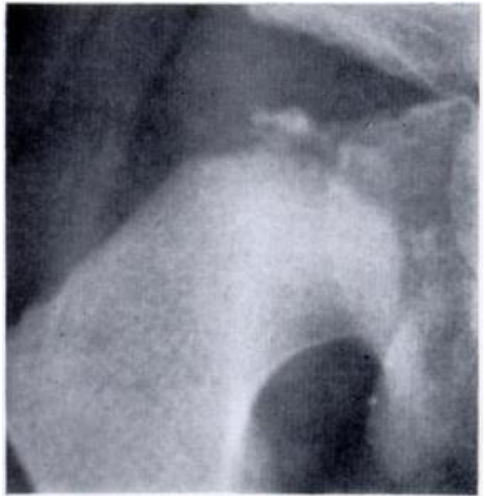

FIG. 26

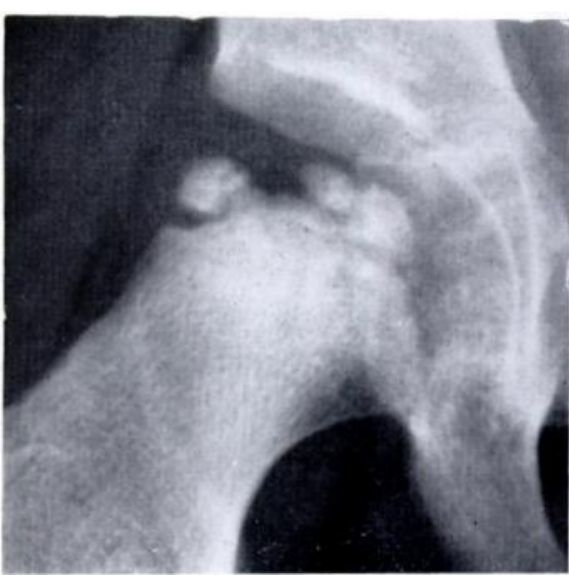

FIG. 27

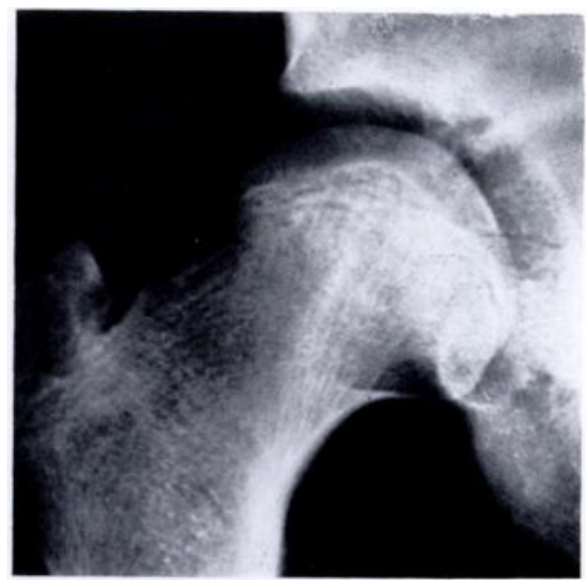

FIG. 28

Group 4. Case $6-$ Age at onset 2 years. Treatment by Snyder sling. Two months of limping. Figures 24 and 25- The epiphysis is small and flattened. There is a large area of calcification lying in lateral part of epiphysis. "Head at risk." Lateral radiograph shows that the whole epiphysis is involved. Figure 26-Eight months later. Epiphysis almost completely absorbed. Figure 27After another fifteen months. Healing well established. The area of calcification is re-forming as part of epiphysis. No lateral subluxation of the head. Figure 28-Seven years later. Healed. Result fair.

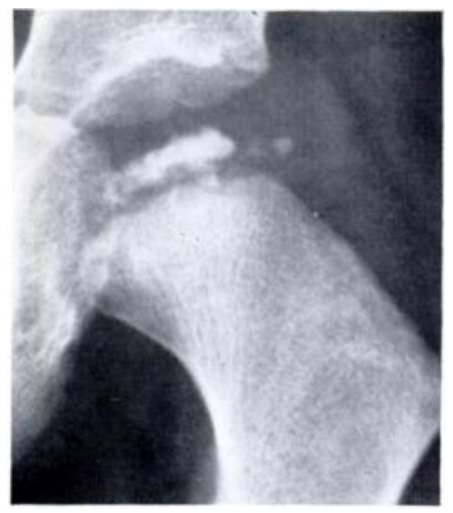

FIG. 29

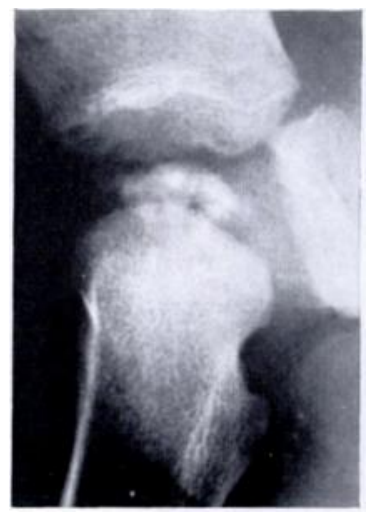

Fig. 30

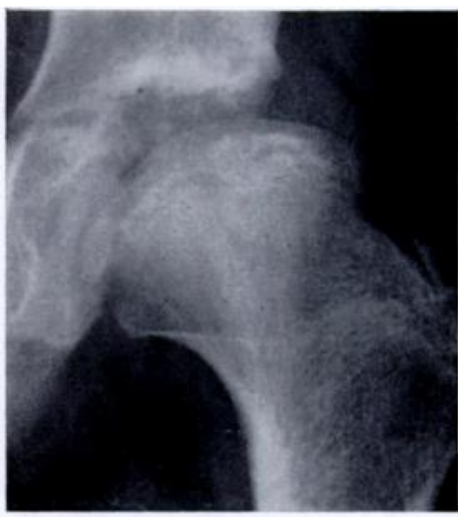

FIG. 31

Group 4. Case 7-Age at onset $3 !$ years. Treatment by Snyder sling. With one year history of limp. Figures 29 and 30-Antero-posterior radiograph shows that the whole epiphysis is involved. Small area of calcification lateral to epiphysis. "Head at risk." The lateral radiograph shows that the whole epiphysis is involved. Figure 31-Ten years on. Healed. Result poor. 
history of injury preceding the onset of symptoms. The onset of symptoms was acute in ten patients, necessitating admission to hospital as an "observation hip".

GROUP RESULTS

General-The general results within the group are shown in Tables I and II. It will be seen that the incidence of a good result steadily declines in direct proportion to the extent to which the epiphysis is involved. There was a corresponding increase in the incidence of poor results. Conventional weight-relieving treatment did not alter the results in Groups 1 and 4 cases, but did appear to influence those of Groups 2 and 3.

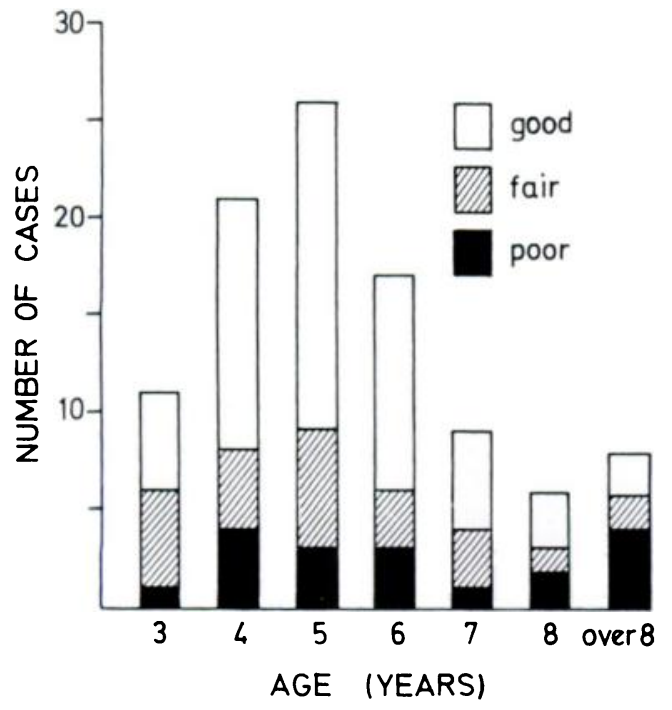

FIG. 32

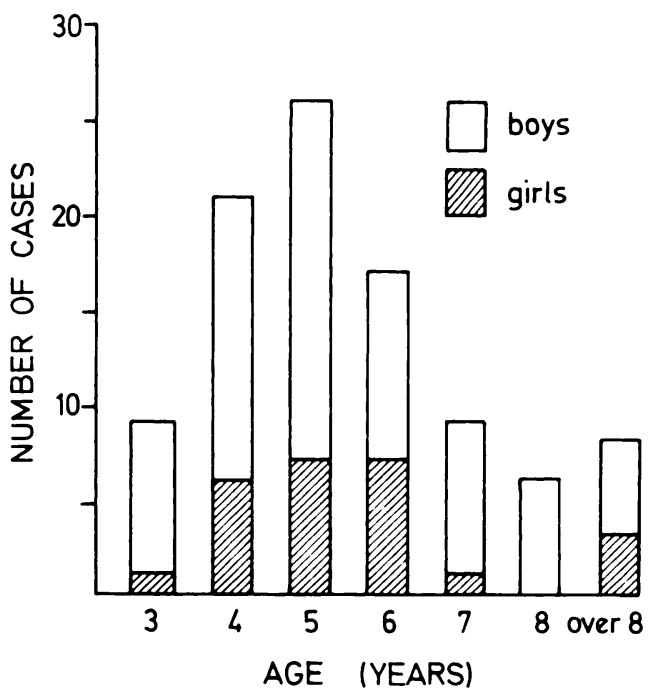

FIG. 33

Figure 32-Results according to age. Figure 33-Sex distribution according to age.

Age and sex-Within each group, age and sex are both shown to influence the overall prognosis. The reasons for this are different. Although the average age at onset is similar in each group, treatment did not seem to influence the outcome in those cases whose symptoms began below the age of four years (Table III). Above this age it does so in Groups 2 and 3. It may be assumed that younger children have a greater growth potential after healing of the disease. Thus, although the initial result at the time of healing may be only fair the end-result may be good (Figs. 16 to 19).

The ratio of boys to girls in this series was $4: 1$, which corresponds to previous series. It also confirms the overall poor prognosis in girls. When the results are broken down into groups most of the girls are to be found in Groups 3 and 4 (Table I). The age distribution for girls is however the same as that for boys (Fig. 33). This is in disagreement with Evans (1958), who explained the poor prognosis in girls on the fact that most of them were in the older age groups. The poor prognosis, however, is due to the fact that they are for the most part in Groups 3 and 4, the outlook for which is worse than the other groups. Within each group the prognosis for girls is approximately the same as for boys (Table IV).

Bilateral cases-Within the groups bilateral cases (Figs. 34 to 39) did not behave differently from unilateral cases with regard to the prognosis for an individual hip. Although in some bilateral cases both heads belonged to the same group, in others they were different and the prognosis for the two heads differed accordingly. This explains why in some cases the result is worse on the side developing the disease while the child is already on bed rest for treatment of the contralateral hip.

VOL. 53 B, NO. 1, FEBRUARY 1971 
TABLE. I

General Comparison of Groups

\begin{tabular}{|lccccccc|}
\hline Group &. & & 1 & & 3 & 4 \\
\hline Number of hips . & $\cdot$ & $\cdot$ & 31 & 31 & 22 & 13 \\
Hips part of bilateral disease & 8 & 4 & 3 & 1 \\
Average age (years) &. &. & 5 & $4 \cdot 5$ & $4 \cdot 5$ & $4 \cdot 5$ \\
Sex ratio . &. &. & $1: 8$ & $1: 6$ & $1: 3$ & $1: 2$ \\
History of injury &. &. & $1: 8$ & $1: 10$ & $1: 8$ & $1: 4$ \\
Untreated cases. &. &. & 16 & 15 & 10 & 5 \\
Treated cases &. &. & 15 & 16 & 12 & 8 \\
\hline
\end{tabular}

TABLE II

Comparison of the Results of Treated and Untreated Cases

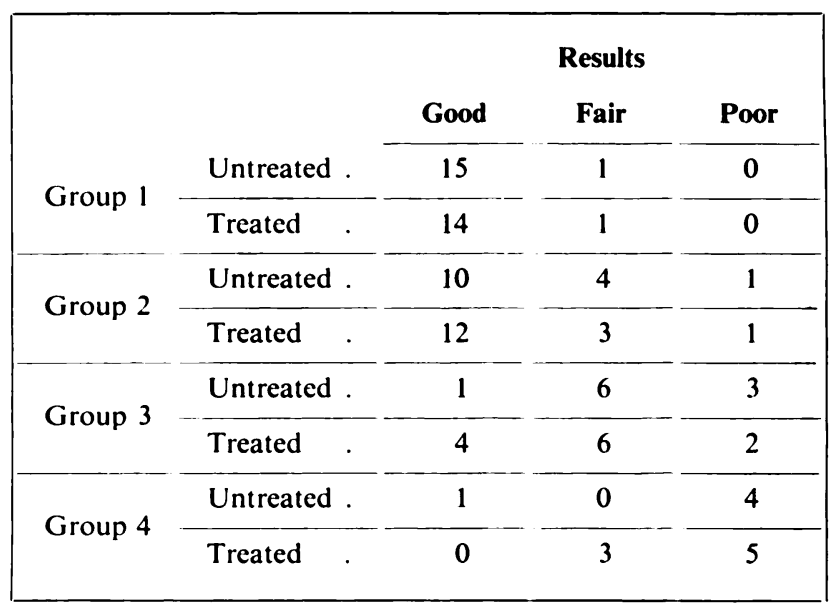

TABLE III

Variation in Results Above and Below the Age of Four Years

\begin{tabular}{|c|c|c|c|c|c|c|c|}
\hline \multirow{5}{*}{ Group 1} & \multirow[b]{4}{*}{ Untreated. } & \multicolumn{6}{|c|}{ Results } \\
\hline & & \multicolumn{3}{|c|}{ Under 4 years } & \multicolumn{3}{|c|}{ Over 4 years } \\
\hline & & Good & Fair & Poor & Good & Fair & Poor \\
\hline & & 5 & 0 & 0 & 9 & 1 & 0 \\
\hline & Treated & 4 & 0 & 0 & 10 & 1 & $\mathbf{0}$ \\
\hline \multirow{2}{*}{ Group 2} & Untreated. & 5 & 1 & 0 & 5 & 3 & 1 \\
\hline & Treated & 3 & 1 & 0 & 9 & 2 & 1 \\
\hline \multirow{2}{*}{ Group 3} & Untreated. & 1 & 4 & 1 & 0 & 2 & 2 \\
\hline & Treated & 1 & 3 & 1 & 3 & 2 & 1 \\
\hline \multirow{2}{*}{ Group 4} & Untreated & 1 & 0 & 0 & 0 & 0 & 4 \\
\hline & Treated & 0 & 1 & 3 & 0 & 2 & 2 \\
\hline
\end{tabular}


Evaluation of arthrography - Satisfactory arthrographs had been performed during treatment in fifty-nine cases. During the routine examination of the plain radiographs of the cases measurements were made of the distance between the growth plate and the acetabulum at its widest point (EA) and the width of the epiphysis (EW) and the findings correlated with the arthrographic appearances (Fig. 40).

TABLE IV

Results According to Sex Within the Groups

\begin{tabular}{|c|c|c|c|c|}
\hline \multirow{4}{*}{ Group 1} & \multirow[b]{3}{*}{ Males } & \multicolumn{3}{|c|}{ Results } \\
\hline & & Good & Fair & Poor \\
\hline & & 27 & 1 & 0 \\
\hline & Females & 2 & 1 & 0 \\
\hline \multirow{2}{*}{ Group 2} & Males & 20 & 6 & 1 \\
\hline & Females & 2 & 1 & 1 \\
\hline \multirow{2}{*}{ Group 3} & Males & 4 & 10 & 3 \\
\hline & Females & 1 & 2 & 2 \\
\hline \multirow{2}{*}{ Group 4} & Males & 0 & 2 & 5 \\
\hline & Females & 1 & 1 & 1 \\
\hline
\end{tabular}

It was noted that in many cases the arthrograph revealed a spherical head whereas in others the head was round but not spherical. In the remainder flattening of the head had occurred. The head is termed "spherical" when the surface of the head forms the greater part of a sphere. When it is "flattened" the articular surface no longer forms part of a sphere (Figs. 41 to 44 ). Nearly all cases had a spherical or round head in the early phases and the presence of flattening at this stage carried a poor prognosis and was only noticed in Groups 3 and 4 . In relation to the measurements it was found that provided the vertical height (EA) was maintained the arthrograph showed the head to be round. If the epiphysial width (EW) was not increased the head was spherical.

At a later stage an arthrograph is of value but its appearance cannot be anticipated by measurement. There is nearly always some reduction in epiphysial height but this is frequently compensated for by adaptive changes in the acetabulum. A hip with an arthrograph which shows severe flattening proceeds to a poor result while a round or spherical head proceeds either to a fair or good result.

When in late cases the need for treatment is being considered, the shape of the cartilaginous head is of some importance. Treatment in the presence of severe flattening is unlikely to be rewarding in contrast to those maintaining a round or spherical appearance. This distinction can only be established by arthrography.

\section{DISCUSSION}

The treatment of Perthes' disease remains controversial. Only a clear understanding of the natural history of the disease in its various manifestations allows an accurate comparison to be made of any form of treatment. It is hoped that the classification suggested in this paper may act as the basis for such a comparison. To justify such a classification the results must show that the prognosis for untreated disease, correlated with the sex incidence and age, differ between the groups. Although the total numbers are small the trends are definable. 


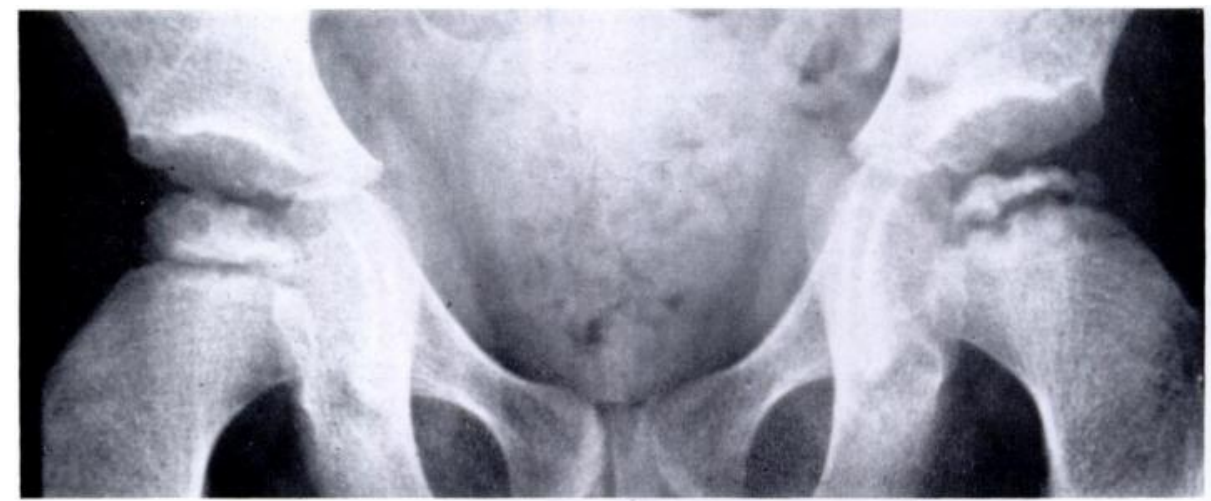

FIG. 34

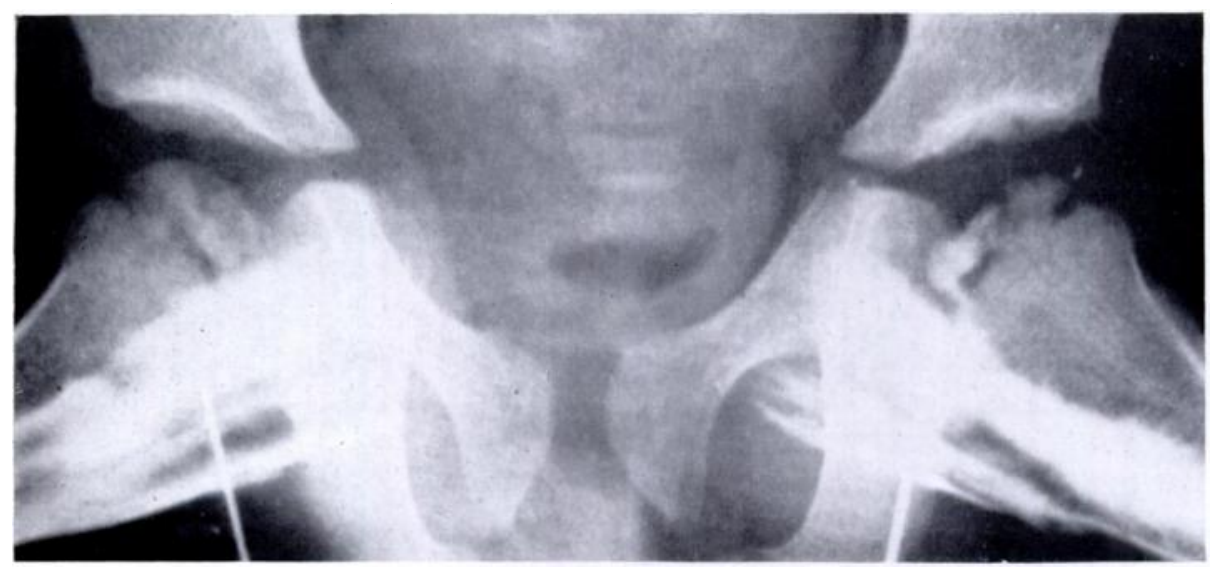

FIG. 35

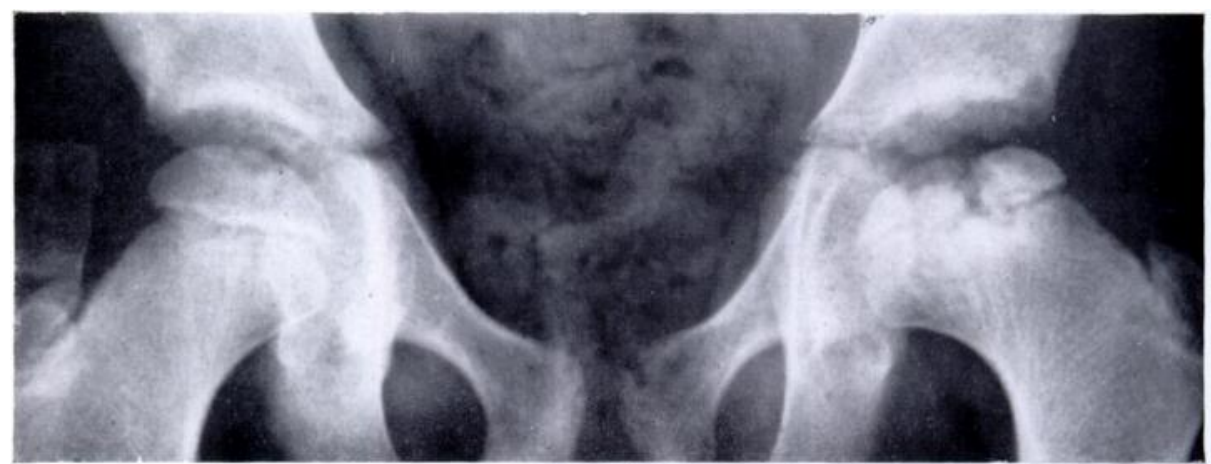

FiG. 36

Bilateral affection. Case 8-Age at onset $3 \frac{1}{2}$ years. No treatment. Figures 34 and $35-$ First radiographs. The left hip shows Group 3 affection. The right hip shows Group 1 affection. Figure 36-Three years later. Good result. 


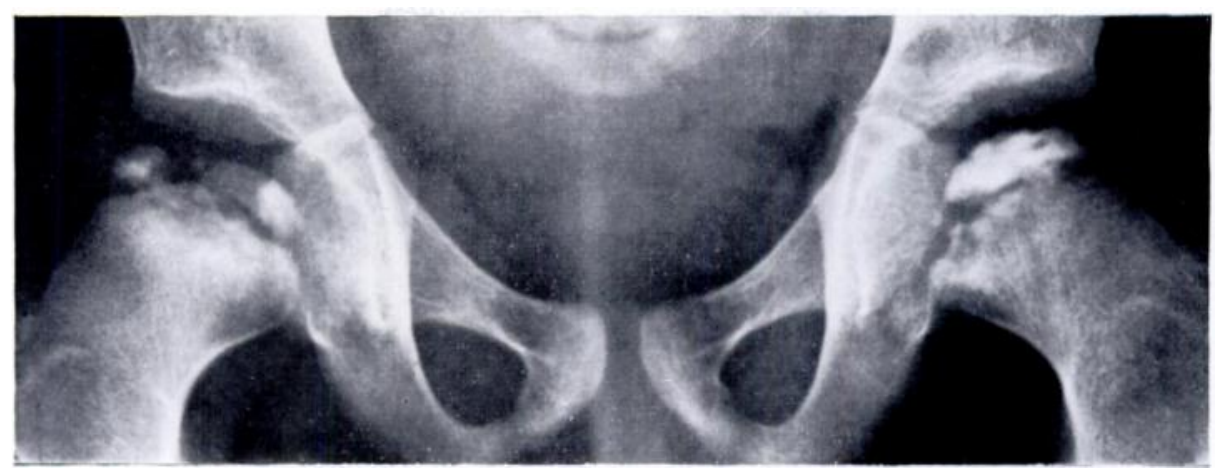

FIG. 37

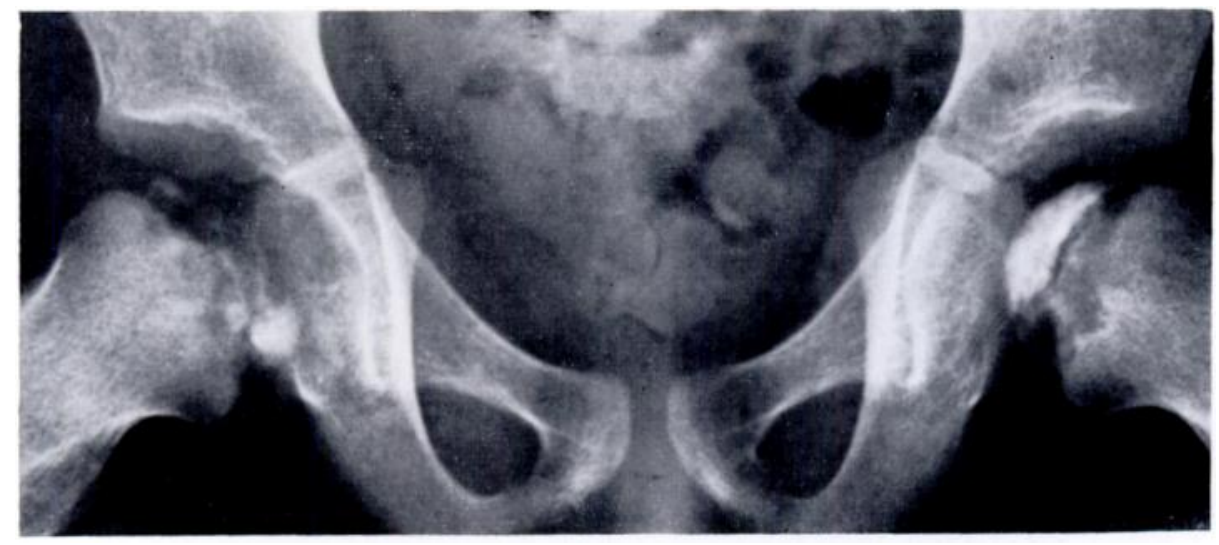

FIG. 38

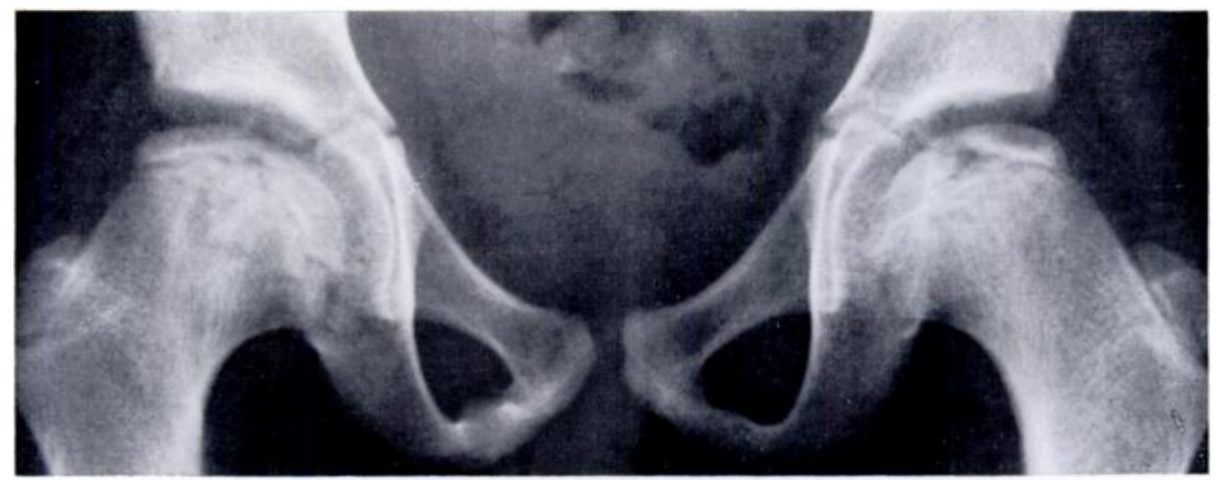

FIG. 39

Bilateral affection. Case 9-Age at onset 3 years. Treatment: right hip by weight-relieving caliper: left hip by Snyder sling. Figures 37 and 38-Initial radiographs. Right hip shows Group 3 affection in healing phase. Left hip shows Group 4 affection. Figure 39-Fourteen months later. Final result fair. 
The chances of a good result steadily decrease from Group 1 to Group 4 although the overall results are similar to those reported by other authors. These results confirm the suggestion of Ponseti (1956) that the prognosis for Perthes' disease is not uniform but depends on the amount of the head involved.

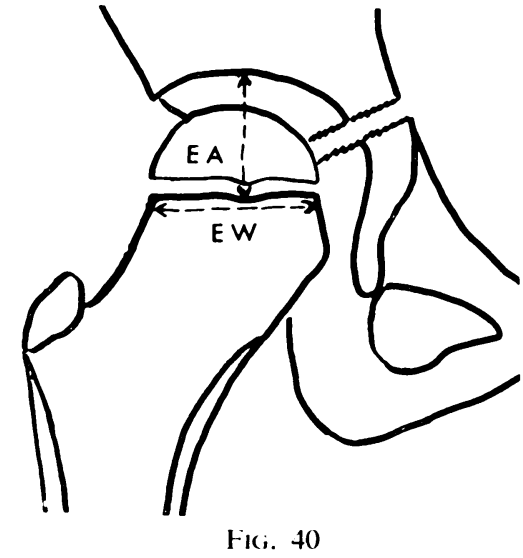

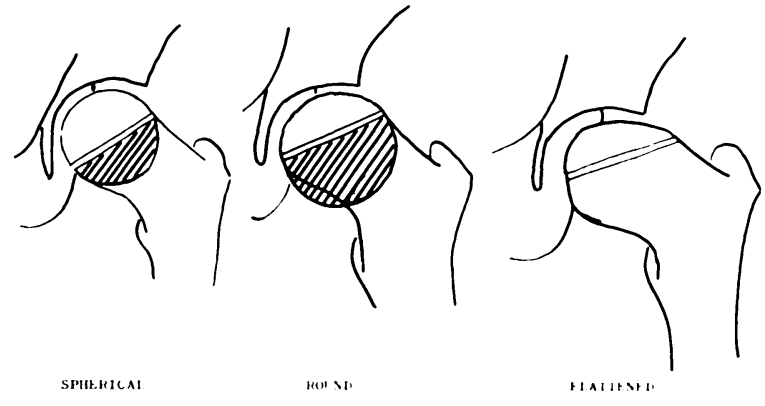

Fig. 41

Figure 40-Drawing to show measurements made on plain radiographs. Figure $41-$ Drawing to show arthrographic appearances. The shaded areas are portion of a sphere not forming part of the head.

Principles of treatment based on this classification-The natural history of untreated Perthes' disease cannot be improved in Group 1 cases, where the results are good almost irrespective of age. The two fair results in this group were both in children over the age of eight years. In children over this age it seems prudent to restrict activity by a weight-relieving caliper, so reducing those inevitable hazards which an unrestricted schoolboy must face.

In patients of Group 2 under the age of four years conventional weight-relieving treatment did not improve the final results, which are still good without treatment. Half the untreated children over this age proceed to a fair or poor result, while non-operative treatment considerably improves this so that three-quarters now have a good result (Table III).

In Group 3 the results are in general fair, less than one-third achieving a good result (Table II). Non-operative treatment does not improve this prognosis in children below the age of four years and only possibly in children over this age (Table III).

In Group 4 three-quarters of patients have a poor result, and non-operative treatment does not improve this in children above or below the critical age of four years (Table IV).

The "head at risk"-Although the results within the groups follow a general trend there are some cases in Group 2 (Figs. 45 and 46) which have a poor result and cases in Groups 3 and 4 which have an unexpectedly good result. In considering these cases it is important to try to diagnose in advance those cases in which considerable collapse of the head may occur. It is possible to recognise those hips, which were considered "at risk", in which there was a high incidence of poor results. There are four radiological signs of value:-

Gage's sign-This is the small osteoporotic segment which forms a transradiant "V" on the lateral side of the epiphysis. This sign is seen on the antero-posterior radiograph and was first described by Courtney Gage (1933) (Fig. 16).

Calcification lateral to the epiphysis-If collapse is occurring a small area of calcification is often seen just lateral to the epiphysis. It may be large (Fig. 24) or small (Figs. 20 and 29). It is in fact the anterior part of the viable lateral fragment. This will be apparent when the head starts to re-form. At this stage this fragment is on the edge of the acetabulum and may not be subject to its remodelling influence, causing the end-result to be fair or more usually poor. Lateral subluxation-The overall prognosis for an epiphysis with one or both of the first two signs may be made worse if there is lateral subluxation of the head. This may be measured as an increase in the infero-medial joint space (Fig. 45). 


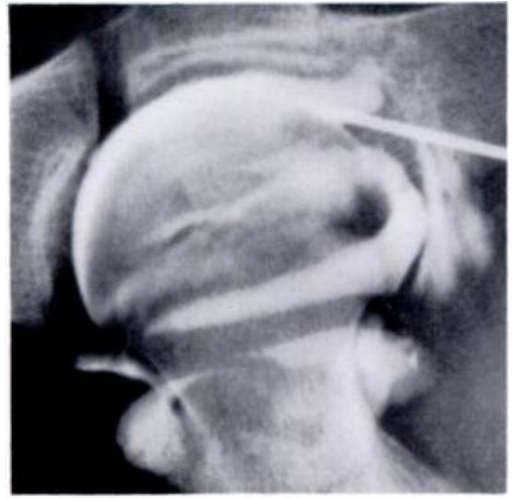

FIG. 42

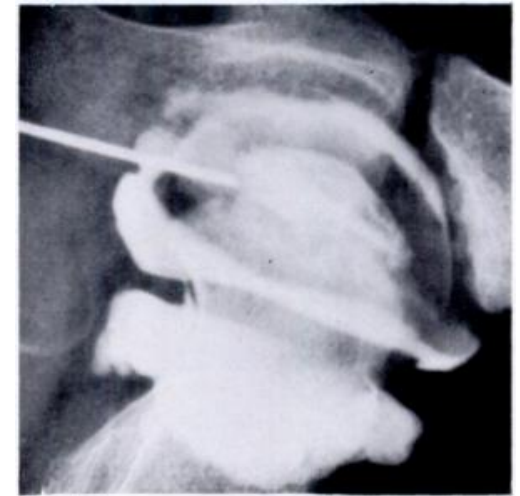

FIG. 43

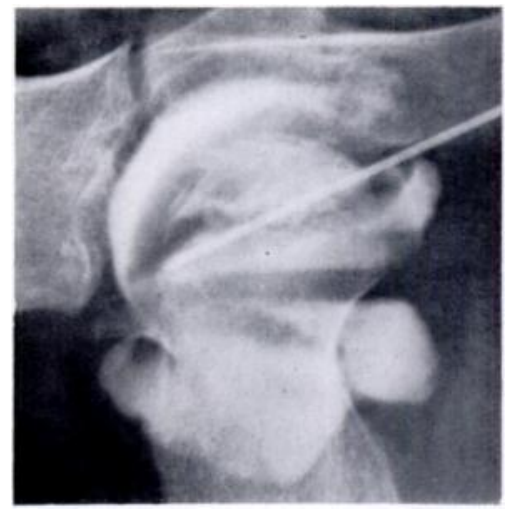

FIG. 44

Figure 42-Arthrograph of spherical head. Figure 43-Arthrograph of round head. Figure 44-Arthrograph of flattened head.

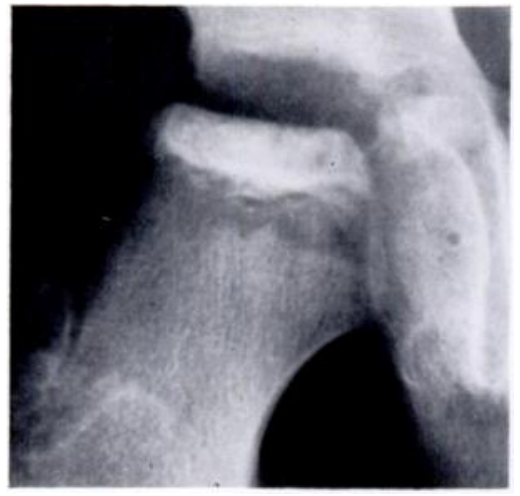

Fig. 45

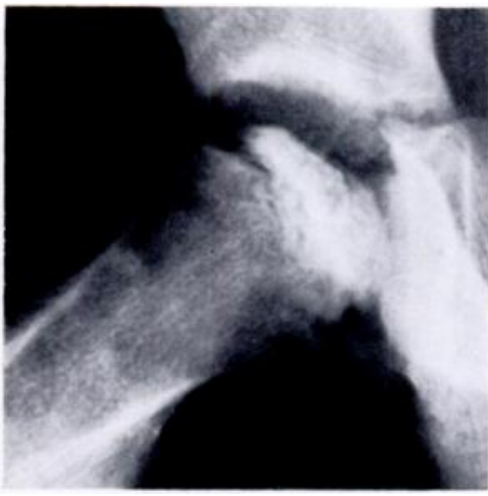

Fig. 46

Case 10-Showing lateral subluxation and horizontal plane of growth plate. Age at onset 5 $\frac{1}{2}$ years. Figure 45-Antero-posterior radiograph. Large sequestrum. Small lateral segment. Lateral subluxation of head. "Head at risk." The growth plate is horizontal. Figure 46 -Lateral radiograph: Group 2 ' $\mathrm{V}$ ' sign present. 
The angle of the epiphysial line-In Groups 3 and 4 there are some cases in which, on the antero-posterior radiograph, the line of the growth plate is transverse (Figs. 45 and 46), while in others this line is inclined to the horizontal plane (Figs. 8 and 24). Forces passing across the hip joint would apply a shearing force to the horizontal plane, encouraging displacement of the lateral part of the epiphysis. This shearing force would be much less if the growth plate were inclined to the horizontal plane. It is pertinent to mention that one of the effects of varus osteotomy is to produce this.

Problems in management-On radiological grounds it is apparent that the involved segment of the epiphysis is anterior. When flattening of the head occurs it is this anterior segment and the viable antero-lateral fragment that are extruded from the joint. This may be confirmed clinically by the fact that medial rotation is the first movement to be limited while lateral rotation remains full. If this is accepted, it follows that the principle of treatment must be first to produce a concentric and congruous hip by containing this segment within the acetabulum and, second, to relieve the hip of undue pressure. The former may be achieved by abduction and medial rotation, and the latter by bed rest or a weight-relieving apparatus. Weight-relieving apparatus can only partially relieve stress from the hip. Trumble (1935) has shown that every time the patient takes a step the abductors contract, transmitting a force through the hip. The Snyder sling produces much better weight relief than a patten-ended caliper but has the serious disadvantage that its prolonged use produces marked shortening. The containment of the head in abduction may be achieved by either an abduction broomstick plaster (Parker 1929, quoted by Harrison and Menon 1966) or by an osteotomy of the varus-derotation type (Axer 1965).

In summary, my impression is that conventional non-operative treatment does not improve the natural history of Group 1 and Group 2 cases occurring in children below the age of four years. It does improve hips in Group 2 in children over this age. In Group 1 the restriction imposed by a caliper seems protective to the older boy accustomed to leading a rough and tumble life. In the remaining groups non-operative treatment is only of doubtful value.

\section{CONCLUSIONS}

1. Eighty-nine cases of Perthes' disease are reviewed.

2. The prognosis varies with the amount of the epiphysis involved.

3. It is possible to assess the amount of epiphysial involvement by a study of the early radiographs. Cases were allocated to four groups on this basis.

4. It is confirmed that both sex and age at the time of diagnosis influence the final prognosis. The reasons for this are discussed.

5. The concept of "the head at risk" is suggested and radiological signs described to diagnose such cases.

6. It is hoped that the classification suggested may in future act as a basis for comparisons of treatment.

I am grateful to Mr G. C. Lloyd-Roberts for permission to study his cases and for his encouragement to do so; to Mrs M. Glen Haig of the Royal National Orthopaedic Hospital for the typing of the manuscript, and to Mr R. J. Whitley of the Institute of Orthopaedics for the preparation of the photographs and figures.

\section{REFERENCES}

Axer, A. (1965): Subtrochanteric Osteotomy in the Treatment of Perthes' Disease. Journal of Bone and Joint Surgery, 47-B, 489.

Evans, D. L. (1958): Legg-Calvé-Perthes' Disease. Journal of Bone and Joint Surgery, 40-B, 168.

Evans, D. L., and Lloyd-Roberts, G. C. (1958): Treatment in Legg-Calvé-Perthes' Disease. Journal of Bone and Joint Surgery, 40-B, 182. 
GaGe, H. C. (1933): A Possible Early Sign of Perthes' Disease. British Journal of Radiology, 6, 295.

Harrison, M. H. M., and Menon, M. P. A. (1966): Legg-Calvé-Perthes' Disease: the Value of Roentgenographic Measurement in Clinical Practice with Special Reference to the Broomstick Plaster Method. Journal of Bone and Joint Surgery, 48-A, 1301.

Murley, A. M. G. (1960): Personal communication.

O'Garra, J. A. (1959): The Radiographic Changes in Perthes' Disease. Journal of Bone and Joint Surgery, 41-B, 465.

Ponseti, I. V. (1956): Legg-Perthes Disease. Journal of Bone and Joint Surgery, 38-A, 739.

Ponseti, I. V. (1961): Legg-Calvé-Perthes Disease-Pathogenesis and Evolution. Journal of Bone and Joint Surgery, 43-A, 261.

SUNDT, H. (1949): Further Investigations Respecting Malum Coxae Calvé-Legg-Perthes with Special Regard to the Prognosis and Treatment. Acta Chirurgica Scandinavica. Supplement 148.

Trumble, H. C. (1935): Weight-bearing Instruments for Walking. British Medical Journal, i, 1070.

Waldenström, H. (1922): The Definite Form of the Coxa Plana. Acta Radiologica, 1, 384.

VOI.. 53 B, NO. 1, FEBRUARY 1971 